\title{
Producing Values: Impact Hub Birmingham as Co-Working and Social
}

\author{
Innovation Space
}

\author{
Paul Long and Annette Naudin \\ Birmingham Centre for Media and Cultural Research, \\ Birmingham City University
}

Cite this chapter as:

Long P., Naudin A. (2019) Producing Values: Impact Hub Birmingham as Coworking and Social Innovation Space. In: Gill R., Pratt A., Virani T. (eds) Creative Hubs in Question. Dynamics of Virtual Work. Palgrave Macmillan, Cham

https://link.springer.com/chapter/10.1007/978-3-030-10653-9 11

\begin{abstract}
Abtract
This chapter explores the character and specificity of Impact Hub Birmingham (IHB) through the lens of its online presentation, assessing its objectives, organisation and activities. Analysis frames IHB in terms of its status as social enterprise, detailing how this manifestation of 'the hub' idea engages individuals in debate and supports a particular idea of entrepreneurship that connects to wider of issues and urban disjuncture. The chapter explores the specificity of Birmingham as a setting for IHB and its commitment to place in relation to a discussion of the hub and co-working idea. A penultimate section locates projects cultivated within IHB in the context of critical perspectives on social enterprise initiatives. Conclusions reflect on the ambition of this iteration of the Impact Hub network, as well as the commitment and verve of its participants that offers a progressive space for social innovation whatever its limits in addressing the city's considerable social and economic problems.
\end{abstract}

\section{Key words}

Impact Hub; co-work; social innovation; Birmingham; cultural enterprise; locality; post-industrial; regeneration; cultural industry clusters; creative city; Digbeth; Local Economic Partnership (LEP); inequality; sweat equity; individualization; isolation; community; curated space; boundaryless worker; habitus of place; Twenty-First Century Town Hall; disruptive innovation; change technologies; creative work; immaterial labour; culturepreneur; Community Interest Company (CIC); Kaur, Immy; social enterprise; entrepreneurship; freelancer; networks; workers; values; mutual benefit. 


\section{Introduction}

Impact Hub describes a network providing co-working spaces with a global reach that stretches 'From Amsterdam to Johannesburg, Singapore to San Francisco' (impacthub.net). Online, it advertises an expanding provision servicing 'over 11,000+ members in 72+ locations' (Ibid). These locations are diverse, including sites across Africa and the Middle East in cities like Harare and Kigali, through South America in Bogota, Oaxaca and Recife or more northerly in Seattle or Honolulu. A recently established 'franchise' site is based in Birmingham UK, the object of investigation for this chapter.

To label a coworking space an Impact Hub might be considered something of a hostage to fortune, especially in light of the avowed mission of the network to create spaces that are equally 'An innovation lab. A business Incubator. A social enterprise community center'(Ibid; for a history and character see: Shiach et al 2017 p. 11ff). As this collection attests, the concept of a hub itself merits some reflection as to its meaning, practices and associations (see also: Virani, 2015; Dovey et al 2016). That the variety of sites in this network set out consciously and pro-actively to produce impact is particularly interesting as a means of understanding the hub idea and the importance of empirical specificity. In this regard, Impact Hub Birmingham (hereafter, IHB) is a suggestive site for scrutiny. It evinces a refreshing social committment when considered in the context of concerns over the implications of co-working and the spaces devoted to them and indeed alongside the banal offer of other providers, commercial or otherwise. The transformative ambition of the global network (Shiach et al 2017 p.17) is echoed 
in IHB's sense of mission: 'to empower a collective movement to bring about change in our city, embracing a diverse range of people and organisations with a whole host of experiences and skills' (birmingham.impacthub.net). As we detail below, this mission inflects the distinctiveness of IHB and the kinds of acivities that its managers organise, as manifest in the titles of events such as People + Passion = Politics: A Guide to Making Change; Social Value on Your Organisation and Radical Childcare.

In this chapter, we follow Dovey et al (2017 p. 25) who note the necessity of a case study approach in apprehending the variety of hub forms. The individuality of sites - even across the Impact Hub network - presents a vista of 'messy relationships between generic description and day to day function' (Dovey et al 2017, p. 25). We explore the character and specificity of IHB through the lens of its online presentation, assessing its objectives, organisation and activities. Our analysis frames IHB in terms of its status as social enterprise, detailing how this manifestation of 'the hub' idea engages individuals in debate and supports a particular idea of entrepreneurship that connects to wider of issues and urban disjuncture. The chapter first considers the City of Birmingham as a setting for this enterprise, proceeding with a discussion of the hub and co-working idea illustrated with insights from IHB's operations. We then outline how IHB's avowed mission is defined by a commitment to this place. The penultimate section places projects cultivated within IHB in the context of critical perspectives on social enterprise initiatives. As we conclude, the ambition of this iteration of the Impact Hub network, as well as the commitment and verve of its participants offers a 
progressive space for social innovation whatever its limits in addressing the city's considerable social and economic problems.

\section{Birmingham: A Tale of Two Cities}

Once the 'workshop of the world', the 'City of a Thousand Trades', Birmingham is a signal post-industrial site whose agents have sought to reinvent and rebrand it. This has been pursued through a new economic rationale and entrepreneurial approach to governance (Cattacin and Zimmer 2016), nurturing the service sector, seeking to develop and attract banking, insurance, and conference hosting businesses (Kennedy 2013). Indeed, much has been invested in re-development, manifest in the building of a flagship projects such as the International Convention

Centre, National Indoor Arena, Bull Ring and most recently the Library of Birmingham, together illustrating an investment in assets that market this site as one offering cultural experience and consumption (Henry et al. 2002). In addition to trompe l'oeil projects and the attraction of high cultural organisations there has been an encouragement of creative enterprise, the development of cultural industry clusters and areas such as Digbeth and Jewellery Quarter (Chapain and Comunian 2010).

Creative England suggests that the city is at the heart of the West Midlands creative and digital development industry and is home to some of the UK's top creative and technology hubs', numbering Impact Hub amongst a wider list of sites: Digital Birmingham; The Custard Factory; Innovation Birmingham and iCentrum (creativeengland.co.uk). While there are significant differences between 
these initiatives, typological similarity lies in the provision of support to start-up companies and SMEs. In so doing, and alongside consultation services, some on this list operate as incubators; others, as IHB does, offer co-working space to individual freelancers and small companies. Here, these enterprises confirm Virani's (2015) description of differences between the hub concept and other common descriptors of contemporary industrial organisation such as clusters or districts. As he writes, 'Where clusters are usually understood due to their spatial organisation, hubs are framed here in regards to what they provide and how they provide it' (Virani 2015 p. 22).

Such activity is evidence of how Birmingham's narrative of remaking is coterminous with the extended validation of 'creativity' and cultural advantage in policy discourse. This is manifest in the idea of the 'creative city' (Landry 2000; Bianchini 2017), the ubiquity of Richard Florida's concept of the creative class (2002/2014) and the prodigious expansion of policy and practice in the cultural economy under New Labour (Hewison 2014). To some degree, these developments can be claimed to have informed aspects of the city's revitalization and success stories ceratainly abound. The Local Economic Partnership (LEP) (2016 p. 5) in its latest plan claims that 'Greater Birmingham' has the highest growth rate of any city region, is the key driver of the nation's, economy outside London and the leading area for foreign direct investment (FDI) in the UK. Developments such as the building of high-speed rail connection to London, means that 'We are experiencing an economic renaissance'. 
From other perspectives however, the city's prospects do not appear so aglow. As Brookes et al (2016 p.88) observe, in spite of local government initiatives in pursuit of social inclusion goals and regeneration of the city centre 'it was acknowledged by all political parties that inequality still existed and lasting change for people living in Birmingham's most deprived neighbourhoods had not been achieved.' They identify how deindustrialization's challenges endure alongside the impact of the financial crash of 2008 and austerity economics. While the city has the youngest population of any of the major cities in Europe: 'Over half of Birmingham is within the most deprived $20 \%$ of England and nearly $40 \%$ is in the most deprived 10\%' (2016 p. 83). Unemployment rates are double the national average, with the city registering the highest figures in the UK amongst young people (those between the ages of 18 and 24). In some areas figures reach $50 \%$ of those eligible for work and is in fact unemployment has become a generational issues.

Cattacin and Zimmer (2016) identify how Birmingham's relationship with 'a unitary state' limits the development of visionary social policies that are independent from those of the central government. Solutions to social problems in the city are thus viewed predominantly in economic terms, promoting growth with less attention to social services. The assumption is that benefits for the latter follow the former. Brookes et al (2016, p. 95) note that while social innovation does occur, it is 'very much at the margins, through opportunistic and short- term support for small-scale projects'. 
This might describe the particular remit of IHB as social enterprise, not just in terms of distinctiveness in relation to other types of co-working space in the city but in its address to these issues and the nature of its commitment to locale.

\section{Inside Impact Hub Birmingham: The Consolations of Co-working}

As with the idea of the hub, and as Butcher $(2016$, p.94) notes, co-working is a fluid concept. Co-working practices take place in a variety of informal and formalised spaces, from the ad-hoc appropriation of sites and meetings in cafes, to achieving fixity in specially designed and sometimes spectacular bespoke buildings. The variety of this sector can be appreciated by comparison between enterprises providing co-working space. The Regus Group, for instance, offers several sites across the globe including in Birmingham, so presenting competition for IHB's offer. While Regus' spaces are advertised as providing proximity to established business zones and access to the attractions of the city, the appeal is generically business-like and the offer functional: 'Drop in whenever you need, with desk space in a professional, shared environment on a first come first served basis' (regus.co.uk). Such organisations manifest the profit-driven, corporate end of this plural sphere of provision. By way of comparison, the offer of not-for-profit IHB is described by member Christopher Jones as distinct from the 'unremarkable' mode of hot-desking one is likely to encounter at places like Regus. At IHB, he identifies a quality that is more than functional, describing 'a certain texture to the environment, a particular grain to the fabric ... cultivating networks of both social and professional value, the two often undivided, whilst generating a collaborative 
and sharing environment with a distinctly non-competitive dimension' (Jones 2016).

Of course, users of Regus' provision may perhaps have similar things to say, as they might of other spaces in the city that are identified by online locator Coworker.com such as Moseley Exchange, The Engine, The Transfer or The Loft. Distinctive here are Jones' lyrical reflections - he is a professional writer - which are offered in an extended blogpost at the online site of IHB. His piece forms part of a rich texture of such accounts, official statements and ideas that convey a sense of the dynamism of this space and its community. This is where a narrative can be garnered that conveys the commitment and personal investment in IHB of its founders. As we discover, some had 'a stint of chasing the bright lights in London', returning to Birmingham and finding like minds in the informal space of contemporary co-work, ie 'the coffee shop to which we owe so many of our founding ideas and brainwaves' (Anon 2014). In making the IHB, its 'young, naive, and independent' founders placed themselves at great risk, having: 'left our jobs, invested everything we had financially, emotionally and physically in bringing this dream to life' (ibid). Such statements attest to a creative investment in IHB's presentation by its founders and managers but also by its members (Butcher 2016, p.101). This suggests how such contributions are a form of 'sweat equity' on the part of the latter group that has mutual benefit in underwriting their location at IHB and faith in its distinctive offer.

As described by Merkel (2015, p.130), the work of managers or 'hosts' oversees the social relationships of workers and use of environment thus turning co- 
working spaces into highly symbolically structured or curated spaces'. IHB's promotion builds from its physical manifestation in terms of the character of its building and the arrangement and population of its space: 'exposed, cleaned-up brickwork ... as many clean lines and panes of glass as possible, creating a modern, naked environment which is both animated and permeable ... underlying any particular arrangement of tables, desks, chair and screens is a sense of the spontaneous' (Jones, 2016). Online testimonies from members about IHB's features and activity articulate the use of this space, its ethos and potential. Alongside the IHB's own website this takes place across those of its members and advocates (no adversaries are apparent) and rich also in the interactions of social media accounts operated by those connected to the space or those participating in its many events. Co-Founder Immy Kaur for instance, has a substantive Twitter status, having nurtured nearly 14000 followers. That she follows an even greater number of accounts indicates her investment in this avenue of communication.

As Gandini (2015) and others have noted, the development of co-working spaces have accentuated individualized sensibilities amongst workers as well as their concomitant isolation. Here, reflections by IHB members offer insights into the realities of co-working, its necessity, challenges and indeed the consolations of this space. Birmingham member Verity M (2014) ponders the contemporary work sphere, that what is missing for the freelancer is a sense of community which jeopardises one’s potential, as ‘Being a photographer can be lonely existence, and I don't believe a creative spirit can be fostered in isolation. We need our peers, we need our contemporaries to be part of the process'. Tara Buckley (2016), a Creative Producer of performance experiences, events and projects records an 
impact of IHB on her practice where 'Having this space has allowed me to dedicate productive time towards projects, which can be difficult as a freelancer, it has shifted the way I think about the work that I do, and as a result I am producing more meaningful projects'. Such instances illustrate how co-working allows individuals to garner appreciation, recognition and ideas from peers (Olma 2012; Merkel 2015). This serves to counteract the precarious nature of freelance work where co-working is conducted in a spirit of mutual exchange and generosity. Thus, events such as Coffee and Change playfully foreground of the importance and availability of quality coffees, teas and cake in IHB discourse, accentuating conviviality but also issues of taste and tastefulness that distinguishes the discerning company and advantage one keeps there. In this way also, IHB invokes the feeling of the coffee shop, the place where so many established (and potential) members have co-worked informally.

At IHB, the creative investments of managers and users contribute to the production of a site that is much more than a functional vessel for the hosting of disparate workers and small businesses, redefining the idea of the entrepreneurial cultural worker. IHB is a layered space of signification reminding one of Doreen Massey's useful formulation that describes places as 'articulated moments in networks of social relations and understandings' (Massey 1994, p. 154). The global, cosmopolitan nature of the Impact Hub network offers one layering of these articulations, informed by a version of working together reified in San Francisco, of coffee shops and the cultural formations associated with 'boundaryless workers' (Brown 2017). While the boundaries usually considered in this label are those between home and work and which have become diluted, 
they might be extended to the apparent lack of situatedness of workers. What does location mean in a globalized economy and co-working culture, mapped by the digital where everything is potentially connected and where boundaries of time, space and culture are permeable? For a network like Impact Hub, what are the similarities but also distinctions in what its mission and activities mean to Khartoum, Kigali or Kings Cross? Certainly, experiences of co-working and the nature of co-working space are not entirely boundaryless. Each is defined too by location, by local culture and its demands. Here then, we can turn to consider the specificity of Birmingham as a location for IHB, its founders, members and the expression of its mission.

\section{The Social Mission of Impact Hub Birmingham}

Fidelity to place is an important feature of Impact Hub as network, something that appealed to the founders of the Birmingham franchise that placed 'global connectivity' alongside the fact that 'all Impact Hub's were locally owned and true to their respective local context' (Anon 2014). In establishing its truth to context, IHB's self-representation evinces a 'habitus of place' (Allen and Hollingworth 2013), at times calling on a form of local chauvinism, if not essentialism. An account of the IHB's origination identifies its inspiration in a TEDx event in the city, although the 'hunger for innovation' addressed there was already 'in our Birmingham blood', infused with the city's reputation: 'Steeped in pioneering history and responsible for patents and moments that have shaped the modern world as we know it' (Anon 2014). The Hub itself is based at The Walker Building in Digbeth, an area still bearing the marks of traditional industry but home too to 
sites synonymous with the ambitions of cultural regeneration and the creative city such as the Custard Factory, The Bond and 'Eastside' (Porter and Barber, 2007). The IHB's home is referred to self-reflexively as a post-industrial site, once home to a company renowned for its owners' philanthropy, progressive approaches to labour (shorter working weeks and good industrial relations), and contribution to building the municipal reputation of Birmingham. Thus, while newly-minted and a product of contemporary economic and socio-cultural realities, IHB's rhetoric affirms a sense of continuity, that 'it's the Walker ethos and commitment to their community at large that has struck a particularly warm and fuzzy chord with us here at the Hub' (Modgil 2015). Likewise, across the kinds of companies and individuals it attracts, and in much of its activities it endorses, IHB connects to the overlooked civic history of Birmingham, a place that once drew international visitors to examine 'The best governed city in the world' (Hunt, xxxix). Here, we are mindful of the work of Virani (2015) and Dovey et al (2017) which suggest that what matters here is the symbolism of IHB's rhetoric about its space and this lineage rather than any of its physical properties. As Dovey et al (2017 p.11) emphasise, its is not location which characterise these enterprises 'but the nature and quality of the productive relationships that occur inside the hub itself'.

Thus, IHB manifests the more social and political commitments associated with co-working (Gandini, 2015). On this point, and as Merkel argues (2015, p. 124), co-working is "not just about working "alone together" or "alongside each other" in a flexible and mostly affordable office space. It is also underpinned by a normative cultural model that promotes five values: community, collaboration, openness, diversity, and sustainability'. IHB makes such values paramount in its 
civic mission of 'Prototyping the Twenty-First Century Town Hall' (Impact Hub Birmingham 2015). In this idea, IHB positions its mission as a direct response to social challenges such as in-work poverty and structural inequality, addressing Birmingham's levels of economic disadvantage, inequalities in health and material deprivation. The possibility of 'transformational change' for this situation is offered in the form of 'disruptive innovation' and 'change technologies' such as open source and crowdsourcing. Thus, what is called for is 'a revolution that reimagines what the "us" is: dissolving the public, civic and private sector divide, disrupting democratic legitimacy and focussing on shared wealth, interdependence, interoperability and a fairer city for all' (Ibid, p.4).

These are high minding ambitions, and they have affective power for those attracted to locating at IHB and for their expectations of the serendipitous encounters likely to take place therein. Verity M (2015) attests to the personal and communal response to this ambition and the perception of its freshness in the context of the city: 'to disrupt the old ways of doing things, and starting to work together from the grassroots to build a greater city, a more collaborative city'. Such instances indicate how 'impact' can be understood here initially, as something concerned with attracting and nurturing the human capital assembled in IHB, of generating mutual endorsement and a collective will toward achieving a civic mission (de Peuter and Cohen, 2015). While members are of course independently constituted and not compelled by the IHB's managers, likewise, the sharing of values informs the kinds of work that each does - or for which is likely to find a welcome. Alongside creative workers like Verity $\mathrm{M}$ and the aforementioned Christopher Jones, many residents are engaged in various other forms of 
'immaterial labour': 'From design skills and public speaking, to coaching and screen-printing' (birmingham.impacthub.net/become-member). Many are occupied by forms of consultation work, seeking to producing affective outcomes in what they do across the civic sphere. Iris Bertz Ltd for instance comprises 'a group of dedicated and experienced artists, designers, organisers, teachers and trainers who are all current practitioners in the creative and educational sector'. They offer 'European Project planning', 'Apprentice Placement programmes', 'Funding Bid development', Workshops and Training', 'Project Management' and 'Arts Projects' (irisbertz.co.uk). The Access Project aids entry to university for disadvantaged if gifted children by pairing them with volunteer tutors (theaccessproject.org.uk). Beatfreeks, now expanded and moved on from the IHB, is 'a creative youth engagement agency. We help young people and brands reach their potential by unleashing their creativity' (www.beatfreeks.com).

The hosting of such enterprises is framed at IHB by the curation of a prodigious range of events that speak directly to its mission and which aim to galvanize engagement with current issues for members and a wider constituency. Inspired by an initiative in Detroit, Birmingham Soup is a group of volunteers with experience in outreach, arts, project management and training who run a regular 'microgranting' dinner in support of the city's creative projects in need of funding. IHB residents are presented with information about the projects, voting on that which fulfils best the brief, that it 'must benefit the Birmingham community ... to be democratic, creative, sustainable and inclusive'. Typical projects cover the arts, land use and urban agriculture schemes, enterprise, social justice initiatives, education, technology, housing and city services. Regular and one-off events are 
indicative of the wider engagement; these include: Beyond Unemployment; United in Hope: 'How To Deal with Hate Crime Toolkit' and Trade School Digbeth: 'a nontraditional learning community that runs on barter and not on a monetary exchange' (birmingham.impacthub.net/whats-on/trade-school-digbeth/).

\section{Assessing Social Enterprise in Impact Hub Birmingham}

Of course, these kinds of events, debates and ideas are produced and take place elsewhere in Birmingham too, but IHB ambitiously places its purpose in contradistinction to 'traditional institutions' such as universities, corporations and local authorities, which 'are struggling to create the rich, safe legitimate trusted and sandboxed environments for shared innovation, with a business model and civic legitimacy essential for the advancement of a collaborative economy and shared wealth' (Impact Hub Birmingham 2015, p.19).

Nonetheless, there is a critical view of such approaches by co-working spaces to consider here. On a general note for instance, Gandini complains (2015, p.194) that much of the literature on co-working sees it as a positive innovation, 'with few dwelling upon empirical findings and rarely offering a critical understanding'. He appears suspicious of the 'culturepreneurs', i.e. skilled knowledge workers with multi-portfolio careers, 'operating as self-entrepreneurs within scarcelyinstitutionalised economies'. Butcher (2016, p. 101), offers a similarly critical view, arguing that whatever the communal sensibility, 'the dominant dispositions within co-working spaces are entrepreneurial. The symbols of community are 
thus adapted for entrepreneurial identity work, and commodified for ambitions towards the capitalist idea of "progress"'.

Such perspectives are prematurely and too generally dismissive: we would argue for a more nuanced understanding of the possibilities of co-working social enterprise as a means of conceptualising a space beyond its compromise by the dictates of the profit motive. Some of this understanding lies in looking beyond the connotations of normative labels. By way of explanation, the term 'social enterprise' does not define a specific model or the legal status of a business; rather, it is used to refer to those that have social objectives as part of their mission, which are addressed in entrepreneurial manner. In the UK, most social enterprises opt to set up as a Community Interest Company (CIC) or co-operatives and operate as a not-for-profit organisation - as is the case with IHB. However, as they need to generate revenue to fulfil their social objectives, they often face a tension between sustainability and the fulfilment of their mission.

Critiques of social enterprise are particularly concentrated on and yet confused over the figure of 'the entrepreneur'. Being enterpreneurial has become synonymous with Schumpeter's ideas of the entrepreneur as 'creative destructor', of being a 'responsible' and 'good citizen' measured in economic terms. The idea celebrates particular modes of the individual, 'driven, determined, ambitious and charismatic' (Leadbeater 1997, p. 11), whose potential is realised in selfemployment and self-interest. Associations of 'social enterprise' also came about in the mid 1990s and in European countries at least, coincidental with the dilution of the welfare state (Anderson et al, 2006; Chell 2007). Overall, this discourse and 
normative ideas of the entrepreneur seeps into the language, tone and descriptions of the socially driven agendas of social enterprises.

On the other hand, within entrepreneurship studies, scholars question limited definitions of the entrepreneur and suggest that rather than studying the figure of the lone hero entrepreneur, we should focus our attention on variant narratives and the nature of entrepreneurship in unusual spaces (Naudin, 2018). Thus, Campbell's (2006, p. 165) exploration of social entrepreneurship considers 'the merits of localized, small-scale, non-heroic enterprise' with an emphasis on women and ethical conduct. This reflects a pro-active approach to intervention in social, ecological and economic development, crafting a 'new entrepreneurial belief system' (Campbell 2006, p.186). These ideas connect with initiatives such as IHB and environments in which alternative forms of entrepreneurship are pursued and tested. Such forms are consciously distinguished from the maledominated, individualistic and commercially driven capitalist narrative that dominates popular media and indeed, much academic literature. Such instances merit closer and more detailed attention for their meanings, achievement and indeed impact.

\section{Conclusions: Impact Hub?}

Cattacin and Zimmer (2017) consider that in Birmingham, while the shift to the entrepreneurial approach to nurturing the service and creative industries offers some means of addressing problems of governance, social innovations emerging in this context are unlikely to solve the 'wicked problems' of the city, of its social 
and cultural fractures. Taking this into account, what then might be the impact of IHB otherwise and how might we assess it?

As Dovey et al suggest (2017 p.17), while hub ventures might produce reports and records that might aid such an assessment, 'the overall picture is of a milieu that concentrates its limited resource on getting its process right rather than evaluating its product'. Certainly, the impact of IHB is is hard to quantify, but might be manifest in the profile of individuals such as Kaur, identified as one of region's top 250 most influential people (Brown 2016). Perhaps IHB's impact can be measured through the numbers who engage with it as members and attendees at its workshops, events and socials. Its first anniversary in 2016 was recorded in a blog post, presenting data that captured events and activities from that year: 140 members - organisations and individual freelancers - were recruited; 382 events were hosted (152 Kg of coffee was consumed!). Beyond these locally situated and referenced activities, its individual identity and innovations connect too with the global network.

IHB's activities have reach but is this the way in which to assess its impact? A site that hosts co-workers might not need to have more than a functional quality, promoting conviviality to give it commercial advantage and to aid sustainability. However, with its mission of civic engagement, IHB explores issues such as unemployment, diversity and childcare with the aim of engaging with and sometimes initiating local debates. This activity seeks to begin a process of social transformation, but it is too early to demonstrate whether this is manifest in general consciousness raising, policy developments, or if any change in social 
inequality is likely to be attributed to such a small player in the city's infrastructure. That said, the impact of such enterprises might gain traction by way of connection with hubs with a sympathetic mission - directly or indirectly by way of their collective contribution to the texture of the city's culture. One local referent for IHB for instance is Birmingham Open Media, described by Dovey at al (2017 p.42) as 'driven by socially engaged practice at the intersection of art, technology and science'. Nonetheless, between themselves, the collective and individual profiles of IHB staff and its members provides models of alternative entrepreneurial identities, revealing diverse narratives, far removed from the rhetoric associated with the celebrated creative economy worker of contemporary policy (Naudin, 2018). Our study suggests that IHB provides an environment in which the tension between sustaining small enterprises, connecting to the locale and negotiating social objectives is reimagined as part of the fabric of a hub. Ultimately, the model IHB presents is not likely to be measured in economic value but in terms of the social values it generates and promotes. In the end, the potential impact is both for social entrepreneurs and those involved in IHB itself and for the city, in raising awareness of its problems, offering experimental and alternative positions as part of its fabric of activity. In the anodyne and relatively toothless landscape of the creative city and cultural industries, this is a positive development. 


\section{References}

Allen, K. and Hollingworth, S. (2013) "'Sticky subjects" or "cosmopolitan creative"? Social class, place and urban young people's aspirations for work in the knowledge economy', Urban Studies, 50(3), 499-517.

Anderson, R. B., Honig, B. and Peredo, A. M. (2006) 'Communities in the global economy: where social and indigenous entrepreneurship meet', in Steyaert, C. and Hjorth, D. (eds) Entrepreneurship as Social Change (Cheltenham and Northampton: Edward Elgar).

$\begin{array}{lllll}\text { Anon } & \text { (2014) } & \text { 'Journey } & \text { So }\end{array}$ https://birmingham.impacthub.net/2014/11/28/journey-so-far/ [Accessed 1 October 2017]

Bianchini, F. (2017) 'Reflections on the Origins, Interpretations and Development of the Creative City Idea', in Van Damme, Ilja, Bert De Munck, and Andrew Miles (Eds). Cities and Creativity from the Renaissance to the Present (London: Routledge).

Brandsen, T., Evers, A., Cattacin, S. and Zimmer, A. (2016) 'Social Innovation: A Sympathetic and Critical Interpretation'. In Bransden et al., Social Innovations in the Urban Context. 
Brandsen, T., Cattacin, S., Evers, A., \& Zimmer, A. (Eds.). (2016). Social Innovations in the Urban Context (Cham: Springer International Publishing).

Brookes, N., Kendall, J. and Mitton, L. (2016) 'Birmingham, Priority to Economics, Social Innovation at the Margins'. In Bransden et al., Social Innovations in the Urban Context.

Brown, J. (2017) 'Curating the "Third Place"? Coworking and the mediation of creativity', Geoforum, 82, 112-126.

Brown, G. (2016) 'The Birmingham Post Power 250’ Birmingham Post 2 APR 2016 http://www.birminghampost.co.uk/business/business-news/birmingham-postpower-250-west-11126796 [Accessed 1 October 2017].

Buckley, T. (2016) 'What's Impact Hub Birmingham?' 10 February. Availabel at < https://birmingham.impacthub.net/2016/02/10/whats-impact-hubbirmingham/ $>$ [Accessed 1 October 2017]

Butcher, T. (2016) ‘Co-working Communities’ in Horne, Ralph, John Fien, Beau B. Beza, and Anitra Nelson (Eds). Sustainability Citizenship in Cities: Theory and Practice (London: Routledge).

Campbell, K. (2009) 'Rekindling the entrepreneurial potential of family business a radical (old-fashioned) feminist proposal', in Hjorth, D. and Steyaert, C. (Eds.) The Politics and Aesthetics of Entrepreneurship (Cheltnenham: Edward Elgar). 
Cattacin, S. and Zimmer, A. (2016). 'Urban governance and social innovations'. In Bransden et al. Social Innovations in the Urban Context.

Chapain, C. and Comunian, R. (2010) 'Enabling and inhibiting the creative economy: the role of the local and regional dimensions in England', Regional Studies, 44 (6), 717-734.

Chell, E. (2008) The entrepreneurial personality: a social construct (Sussex: Routledge).

de Peuter, G. and Cohen, N. (2015) 'Emerging Labour Politics in Creative Industries', in The Routledge Companion to the Cultural Industries, Oakley, K. and O’Connor, J. (eds) (Abingdon: Routledge).

Dovey, J., Pratt, A.C., Moreton, S., Virani, T.E., Merkel, J. and Lansdowne, J., (2016) The Creative Hubs Report: 2016.

Florida, R. (2014) The Rise of the Creative Class--Revisited: Revised and Expanded. (New York: Basic Books).

Gandini, A. (2015) 'The rise of coworking spaces: A literature review', Theory and Politics in Organization, 15(1), 193-205. 
GBSLEP (2016) Greater Birmingham For A Greater Britain Gbslep Strategic Economic Plan 2016-2030. Available at: <http://centreofenterprise.com/sep2016/>

Henry, N., McEwan, C. and Pollard, J. (2002) 'Globalization from below: Birmingham - postcolonial workshop of the world?' Area, 34 (2), 117-127.

Hewison, R. (2014). Cultural Capital: the rise and fall of creative Britain (London and New York: Verso Books).

Hunt, T. (2005). Building Jerusalem: the rise and fall of the Victorian city (London: MacMillan).

Impact Hub Birmingham (2015) Mission Roadmap: Prototyping the 21st Century $\begin{array}{llll}\text { Town } & \text { Hall. } & \text { at: } & \text { a }\end{array}$ https://issuu.com/impacthubbirmingham/docs/impact hub birmingham missi on roadm $>$ [Accessed 1 October 2017]

Johar, I and Kaur, I (2015) '1-mission-3-stories-5-lessons-5-plans' < https://birmingham.impacthub.net/2015/05/17/1-mission-3-stories-5-lessons5-plans/> [Accessed 1 October 2017]

Jones, Christopher (2016) 'Co-working at Birmingham's Hub: Feeling the Impact' < $\quad$ https://birmingham.impacthub.net/2016/07/18/co-working-atbirminghams-hub-feeling-the-impact/>[Accessed 1 October 2017]. 
Kennedy, L. (Ed.). (2004/2013). Remaking Birmingham: The Visual Culture of Urban Regeneration (London: Routledge).

Landry, C. (2000) The Creative City: A Toolkit for Urban Innovators (UK: Earthscan).

M, V. (2014). 'Creativity, Collaboration and Community: Falling in love with Birmingham'. 13 December. Available at < https://medium.com/hubbirmingham/creativity-collaboration-and-community-falling-in-love-withbirmingham-4a2b889139f9 > [Accessed 1 october 2017]

Massey, D. (1994). Space, place and gender (Minneapolis : University of Minnesota Press).

Merkel, J. (2015). 'Coworking in the city'. Ephemera, 15(2), 121-139.

Modgil, K. (2015). 'A history of Thomas Walker and Son'. Available at: <http://birmingham.impacthub.net/2015/05/05/a-history-of-thomas-walkerand-son/> [Accessed 1 October 2017]

Naudin, A. (2018) Cultural Entrepreneurship: The cultural worker's experience of entrepreneurship (London: Routledge). 
Olma, S. (2012). The Serendipity Machine: a disruptive business model for society 3.0. (Utrecht: Society 3.0 Foundation).

Porter, L. and Barber, A. (2007). 'Planning the cultural quarter in Birmingham's Eastside', European planning studies, 15(10), 1327-1348.

Shiach, ME, D. Nakano, T. Virani, and K. Poli. (2017)"Report on Creative Hubs and Urban Development Goals (UK/Brazil)." Creative Hubs and Urban Development Goals (UK/Brazil).

Virani, T. E. (2015) Re-articulating the creative hub concept as a model for business support in the local creative economy: the case of Mare Street in Hackney. Creativeworks London Working Paper Series. 